\title{
Executive Action to Expand Health Services in the Biden Administration
}

Timothy M. Westmoreland

Georgetown University Law Center, westmort@law.georgetown.edu

Maxwell Gregg Bloche

Georgetown University Law Center, bloche@law.georgetown.edu

Lawrence O. Gostin

Georgetown University - Law Center - O'Neill Institute for National and Global Health Law, gostin@law.georgetown.edu

This paper can be downloaded free of charge from:

https://scholarship.law.georgetown.edu/facpub/2349

https://ssrn.com/abstract=3775798

The Journal of the American Medical Association, Vol. 325, No. 3, Pp. 217-218.

This open-access article is brought to you by the Georgetown Law Library. Posted with permission of the author. Follow this and additional works at: https://scholarship.law.georgetown.edu/facpub

Part of the Health Law and Policy Commons, and the Law and Economics Commons 
Timothy M.

Westmoreland, JD

Georgetown University

Law Center,

Washington, DC.

\section{Gregg Bloche, MD,}

JD

Georgetown University

Law Center,

Washington, DC.

Lawrence 0. Gostin,

JD

O'Neill Institute for National and Global Health Law,

Georgetown University, Washington, DC.

$\epsilon$

Viewpoint page 215 and Editorial page 227

\section{Corresponding}

Author: Lawrence O.

Gostin, JD, O'Neill

Institute for National

and Global Health Law,

Georgetown University,

600 New Jersey Ave

NW, McDonough 568 ,

Washington, DC 20001

(gostin@georgetown. edu).
President Biden's health platform is ambitious, encompassing a public insurance option, a reduced age of eligibility for Medicare, and expanded tax credits to subsidize premiums. Yet, with divided government, he may be unable to achieve bold health reforms. However, his administration can substantially improve health care access through executive action. In this Viewpoint, we propose a series of measures that could increase access to insurance coverage and health care that are achievable under the Affordable Care Act (ACA) and Medicaid.

\section{ACA Insurance Marketplaces}

The Trump administration issued regulations that undermined the functioning of the insurance marketplaces established in the ACA, resulting in an estimated 2 million people losing coverage prior to the coronavirus disease 2019 (COVID-19) pandemic. By late summer of 2020, economic shocks related to the pandemic left millions more uninsured. ${ }^{1}$

Limit "Short-term" Coverage

The ACA permitted sale of inexpensive "limited-duration" insurance with preexisting condition and other exclusions. These plans were intended only as transient coverage between jobs. The Obama administration limited enrollment

\section{President Biden's most ambitious plans may be beyond reach in an era of divided government. Yet, he has broad executive powers to expand access to health services and reduce health inequities.}

in the plans to 3 months so they would not channel healthier peopleaway from ACA-qualifying insurance. ${ }^{2}$ The Trump administration removed this limit, permitting coverage for up to 3 years. As a result, many younger, healthier consumers left comprehensive ACA-qualifying plans in favor of lower-priced coverage with large gaps in coverage. By drawing healthier people away from ACA-qualifying plans, short-term plans make ACA-qualifying coverage less affordable; moreover, short-term plans make lower payments to health care institutions, and insurance brokers often charge high commissions. Short-term plans, therefore, erode insurance markets while delivering low value to patients. The Biden administration should restore the 3-month limit on short-term coverage.

Direct Consumers to Insurance Exchanges

The Trump administration encouraged insurance brokers and health plans to sell directly to consumers, bypassing the insurance exchanges in the ACA. This enabled dubious sales tactics, encouraged by high sales commissions, including marketing "short-term" plans to Medicaid-eligible individuals and providing incomplete, distorted comparisons between coverage options. ${ }^{3}$ Consequently, the essential role of the exchanges as objective information clearinghouses has eroded. This has also undercut the ACA's "no wrong door" policy, which established exchanges as points of entry for the law's full range of coverage options and subsidies. The Biden administration should strictly limit the ability to bypass exchanges and rescind State Innovation Waivers that circumvent exchanges.

\section{Make Plan Enrollment Easier}

The Trump administration made it more difficult to enroll in ACA-qualified plans by reducing the annual open enrollment period from 90 to 45 days, closing Healthcare.gov for 12 hours on Sundays, and decreasing public outreach funding for the federal exchange by $90 \%$. The administration also declined to reopen federal exchange enrollment (via a Special Enrollment Period) to accommodate people who lost jobs and coverage due to COVID-19. President Biden should restore 90-day open enrollment (with 24/7 online access), commence a COVID Special Enrollment Period, and reinstate funding for public outreach and in-person enrollment.

Compensate Insurers for Reducing Lower-Income Consumers' Cost-Sharing The ACA requires qualified plans to reduce out-of-pocket costs (deductibles and copayments) for consumers with income below $250 \%$ of the federal poverty line who purchase "Silver" plans (lower-priced coverage with high cost-sharing). The law requires the federal government to reimburse insurers for this cost but, in 2011, Congress declined to appropriate funds. President Obama invoked his executive authority to compensate insurers, but President Trump eliminated these payments. Insurers found a workaround by selectively raising Silver plan premiums ("Silver loading") to recover their losses. But Silver loading distorts plan price and value and disadvantages Silver plan purchasers who are ineligible for premium subsidies. President Biden should restore compensation payments to insurers.

Empower Health Plans to Address Socioeconomic Determinants of Health

COVID-19 has vividly shown how social and environmental circumstances affect health. The Biden administration 
should leverage the ACA to allocate resources to address nonmedical determinants of disease. Some health plans are already helping subscribers secure food and shelter. ${ }^{4}$ Embedding attorneys, patient advocates, and social workers in clinics and hospitals is one promising strategy already being pursued by Medicaid. ${ }^{5}$ Advocates could work to abate mold, dust, toxic chemicals, and other hazards in and around living spaces, while connecting patients to food, housing, and employment assistance. ACA waivers for payment models that include such services could catalyze progress. The US Department of Health and Human Services (HHS) should undertake a systemic review of ACA flexibilities to address social and environmental determinants of health.

\section{Medicaid Eligibility and Services}

Medicaid is the most versatile and capacious health insurance program. With the related Children's Health Insurance Program, Medicaid provides coverage for 75 million people, including more than $40 \%$ of newborns and $60 \%$ of nursing home residents. ${ }^{6}$ It also provides a safety net for people in the midst of health crises, such as hurricanes, forest fires, and epidemics. Racial and ethnic minorities are disproportionately beneficiaries of Medicaid, and no program reaches more low-income people. President Biden can use creative executive action to reform and expand this far-reaching program, which serves the most vulnerable members of society, as well as hard-pressed health care institutions.

\section{The COVID-19 Pandemic}

The Families First Coronavirus Response Act increased the federal matching rate for Medicaid and Children's Health Insurance Program by 6.2 percentage points. However, COVID-19 will cost states far more, with governors requesting at least double. However, relief funding lasts only while there is a declared emergency, which is due to expire on inauguration day. President Biden should extend the emergency declaration, authorizing urgently needed aid to state Medicaid programs. HHS is also seeking to end protections against increased benefit cost-sharing during the emergency. The Biden administration should reinstate those protections.

\section{Roll Back Harmful Waivers}

Medicaid allows states to conduct research and demonstration waivers to "promote Medicaid's objectives." Yet, HHS has solicited waivers that reduce eligibility and services, including requiring low-income in dividuals to meet work requirements, pay premiums or cost-sharing, and comply with burdensome processes that lead to losses in coverage. Many waivers are tied up in litigation, including a pending Supreme Court review of Medicaid work requirements. The Biden administration should withdraw approvals and solicitations for new proposals that burden eligibility or reduce services. The new HHS secretary should instead solicit constructive waivers, such as those to reduce maternal mortality and to extend postpartum coverage. Such waivers could improve services and reduce socioeconomic disparities.

\section{Simplify Eligibility and Enrollment}

Medicaid allows states to affirmatively help people obtain coverage, which is especially important during the COVID-19 pandemic and a slumping economy. For example, states could offer temporary coverage while Medicaid applications are pending and could improve basic outreach and assistance, such as contacting beneficiaries when their communications are returned in the mail.

\section{Action Requiring Congress}

Beyond executive action, President Biden should work with Congress toward universal access to health services. The ACA could be strengthened to include a public insurance option, available to lowincome individuals without charge or with reduced premiums. Expanded federal subsidies for purchase of private coverage would also significantly increase access.

The Biden administration could also work with Congress on Medicaid reforms. Most important would be increased federal matching funds, at least during the course of the pandemic. Additionally, 12 states have not expanded Medicaid programs to cover all low-income individuals. Federal economic incentives could encourage the remaining states to expand their programs. Doing so would be a vital step in expanding services and reducing health care disparities.

President Biden's most ambitious plans may be beyond reach in an era of divided government. Yet, he has broad executive powers to expand access to health services and reduce health inequities. President Biden's executive actions will be challenged in courts, but can be crafted to survive judicial scrutiny. Each of these proposed executive actions is fully consistent with the aims of the ACA and Medicaid, which are to bring essential health services to most people in the US, with particular attention to the most disadvantaged.

\section{ARTICLE INFORMATION}

Conflict of Interest Disclosures: Dr Bloche reported participating in the conceptualization of President Obama's health care reform plan (and speaking to health policy and other audiences on behalf of the plan) during the 2007-2008 presidential campaign and the transition. No other disclosures were reported.

\section{REFERENCES}

1. Bivens J, Zipperer B. Health insurance and the COVID-19 shock. Economic Policy Institute. August 26, 2020. Accessed December 17, 2020. https:// www.epi.org/publication/health-insurance-andthe-covid-19-shock/
2. Keith K. The short-term, limited-duration coverage final rule: the background, the content and what could come next. HealthAffairs. August 1 2018. Accessed December 17, 2020. https://www. healthaffairs.org/do/10.1377/hblog20180801. 169759/

3. Straw T. "Direct Enrollment" in marketplace coverage lacks protections for consumers, exposes them to harm. Center on Budget and Policy Priorities. Published March 15, 2019. Accessed December 17, 2020. https://www.cbpp.org/ research/health/direct-enrollment-in-marketplacecoverage-lacks-protections-for-consumers-exposes

4. Accountable health communities model. Centers for Medicare \& Medicaid Services. Updated
November 6, 2020. Accessed December 17, 2020. https://innovation.cms.gov/innovation-models/ ahcm

5. Tapping into Medicaid financing streams. National Center for Medical-Legal Partnership webinar. June 10, 2019. Accessed December 17, 2020. https://medical-legalpartnership.org/mlpresources/medicaid-financing/

6. Rudowitz R, Garfield R, Hinton E. 10 Things to know about Medicaid: setting the facts straight. Kaiser Family Foundation. Published March 6, 2019. Accessed December 17, 2020. https://www.kff.org/ medicaid/issue-brief/10-things-to-know-aboutmedicaid-setting-the-facts-straight/ 